\title{
Current dietary salt intake of Japanese individuals assessed during health check-up
}

\author{
Akiko Toda, Yuko Ishizaka, Mizuki Tani and Minoru Yamakado \\ Excess salt intake is a risk factor for increased blood pressure (BP) and hypertension. To prevent hypertension, the reduction \\ of salt intake is promoted in many countries. For people with hypertension or cardiovascular disease (CVD), a more severe \\ restriction of salt intake is indispensable. Japanese individuals consume high quantities of salt, and it is thus important to \\ determine the degree to which the salt intake of these individuals has been restricted. Here, we investigated the current level \\ of salt consumption of Japanese individuals using data obtained during annual health check-ups. A total of 10762 individuals \\ were assessed who underwent annual health check-ups at our institution in 2011. The estimated daily salt intake (EDSI) was \\ calculated using spot urine samples. The average EDSI was $7.83 \pm 2.02 \mathrm{~g}$ per day. BP increased in proportion to the EDSI, and \\ multivariate logistic regression analysis showed that the EDSI was a significant and independent risk factor for hypertension. The \\ average EDSI of the subjects with hypertension or a history of CVD was higher than that of the subjects without these diseases. \\ The subjects who drank more heavily showed higher EDSIs. This study demonstrated that the average EDSI of the subjects \\ needing to restrict their salt intake because of past or present illnesses was high. To achieve adherence to the recommended \\ reduction of salt intake, more efforts are required.
}

Hypertension Research (2015) 38, 163-168; doi:10.1038/hr.2014.154; published online 30 October 2014

Keywords: lifestyle; prevention \& control; salt

\section{INTRODUCTION}

Excess salt intake is a risk factor for the onset and development of hypertension, ${ }^{1,2}$ and the restriction of salt intake has been shown to lower the blood pressure (BP) and prevent hypertension. ${ }^{3-6}$ Salt elimination, as stimulated by a diuretic agent, can also decrease BP. ${ }^{7}$ Many studies have shown that individuals with cardiovascular disease (CVD) often consume more salt and that excess salt intake is a strong risk factor for CVD. ${ }^{8-10}$ The restriction of salt intake is thus essential for preventing the onset and recurrence of several hypertension-related diseases.

Recommended salt intake values vary in different countries. For example, in the United States, the recommended intake is $3.8 \mathrm{~g}$ per day, ${ }^{11}$ and in the United Kingdom, it is $6 \mathrm{~g}$ per day. ${ }^{12}$ One of the reasons for this difference is that the effects of salt intake reduction on morbidity rate differ among races. For example, black individuals have a high rate of hypertension and CVD, ${ }^{13,14}$ and salt intake restriction among blacks is more beneficial compared with non-blacks. ${ }^{15}$ In addition, environmental factors (such as an individual's home and community) and factors associated with socioeconomic status (such as education and household income) influence salt intake.,16

The Japanese Society of Hypertension Guidelines for the Management of Hypertension (JSH2009) highly recommends that daily salt intake should be below $6 \mathrm{~g}$ per day. ${ }^{17}$ However, according to a 2010 report by the Japanese Ministry of Health, Labor and Welfare, the average daily intake among Japanese men is $11.4 \mathrm{~g}$ per day, and that among Japanese women is $9.8 \mathrm{~g}$ per day. ${ }^{18}$ It is well known that salt intake is high in Japan compared with other countries because traditional Japanese seasonings, such as soy sauce, miso and dried fish products, contain high amounts of salt. ${ }^{19}$ It has been reported that the salt intake of Japanese individuals is associated with higher incidences of stroke and CVD. Those consuming high levels of salt (17 g per day) show a twofold higher risk of mortality due to stroke compared to those consuming lower levels ( $10 \mathrm{~g}$ per day). ${ }^{20}$ An additional study of Japanese individuals has shown that the multivariable hazard ratios of higher salt intake ( $8 \mathrm{~g}$ per day) to lower salt intake ( $3 \mathrm{~g}$ per day) for stroke and CVD are 1.55 and 1.42, respectively. ${ }^{21}$ Despite the clear need to reduce salt intake in the Japanese population, it is difficult because of the salty local cuisine.

To achieve the effective reduction of salt intake, information regarding the actual intake of Japanese individuals must be obtained, and this was investigated in the present study.

\section{METHODS}

Study population

All subjects underwent annual health check-ups at The Center for Multiphasic Health Testing and Services, Mitsui Memorial Hospital in Tokyo, Japan. The number of healthy subjects who underwent an annual health check-up at our institution in 2011 was 10762 . 
Data analysis

Information regarding sex, birth date, lifestyle and medical history for each subject was obtained through a self-administered questionnaire and confirmed through an interview with a physician. BP was measured twice using an automatic device after several minutes of rest in a seated position. The average value was used as the BP reading. Body height and weight were measured during hospital visits. Body mass index was calculated using the following equation: body weight $(\mathrm{kg}) /$ body height $(\mathrm{m})^{2}$.

Blood and urine samples were collected after an overnight fast. The subjects provided urine samples immediately after arriving at our institution at between 8:00 and 10:00 a.m. high-density lipoprotein cholesterol, low-density lipoprotein cholesterol, triglycerides, glucose and creatinine were measured enzymatically. HbAlc was measured by latex agglutination immunoassay. Sodium was measured by ion-selective electrode method. The estimated glomerular filtration rate was calculated using a version of the Modification of Diet in Renal Disease equation modified for Japanese individuals as follows ${ }^{22}$ : glomerular filtration rate $\left(\mathrm{ml} \mathrm{min}^{-1} 1.73 \mathrm{~m}^{-2}\right)=194 \times \mathrm{age}^{-0.287} \times$ serum creatinine $\left(\mathrm{mg} \mathrm{dl}^{-1}\right.$, the enzymatic method $)^{-1.094} \times(0.739$ if female $)$.

The estimated daily salt intake (EDSI) was calculated using the following equation $^{23}$ : EDSI (g per day $)=21.98 \times(($ natrium in urine $/($ creatinine in urine $\times$ 10) $\times(-2.04 \times \text { age }+14.89 \times \text { body weight }+16.14 \times \text { body height }-2244.45)^{0.392} \times$ 0.0585 .

This study was approved by the ethics committee of our institution, and informed consent was obtained from each subject.

\section{Statistical analysis}

All statistical analyses were performed using SAS (Dr SPSS II, SAS Institute, Cary, NC, USA). The statistical significance of the differences in the subjects' characteristics was determined using an unpaired $t$-test or one-way analysis of variance (ANOVA). Hazard ratios with 95\% confidence intervals were calculated using multivariate logistic regression analysis. A $P$-value of $<0.05$ was considered significant.

\section{RESULTS}

Study population

Our study population consisted of 10762 subjects who underwent an annual health check-up in 2011 (6452 men and 4310 women, $55.0 \pm 10.7$ years old). Their baseline characteristics are shown in Table 1. A total of 1587 subjects were on medication for hypertension.

\section{Correlation between BP and salt intake}

The average salt intake was $7.83 \pm 2.02 \mathrm{~g}$ per day; that of the men was $8.00 \pm 2.04 \mathrm{~g}$ per day, and that of the women was $7.58 \pm 1.97$ g per day.

Table 1 Baseline characteristics of study population $(n=10762)$

\begin{tabular}{|c|c|}
\hline & Value \pm s.d. or $\%$ \\
\hline Men $(\%)^{a}$ & 60.0 \\
\hline Age (years) & $55.1 \pm 10.8$ \\
\hline Body mass index (\%) & $22.8 \pm 3.3$ \\
\hline Systolic blood pressure $(\mathrm{mm} \mathrm{Hg})$ & $123.0 \pm 18.1$ \\
\hline Diastolic blood pressure ( $\mathrm{mm} \mathrm{Hg}$ ) & $77.6 \pm 11.2$ \\
\hline HDL-cholesterol (mg dl-1) & $63.0 \pm 15.5$ \\
\hline LDL-cholesterol (mg dl${ }^{-1}$ ) & $123.1 \pm 29.7$ \\
\hline Triglyceride $\left(\mathrm{mg} \mathrm{dl}^{-1}\right)$ & $113.1 \pm 87.1$ \\
\hline HbA1c (NGSP) (\%) & $5.81 \pm 0.6$ \\
\hline Blood sugar (mg dl-1) & $100.4 \pm 18.3$ \\
\hline eGFR (ml min $\left.1.73 \mathrm{~m}^{-2}\right)$ & $76.0 \pm 13.9$ \\
\hline
\end{tabular}

Abbreviations: eGFR, estimated glomerular filtration rate; HDL, high-density lipoprotein;

LDL, low-density lipoprotein; s.d. standard deviation.

All patients participated in this study were Japanese.

aThe proportion of men was showed as percentage and others were showed as value.
The correlation between EDSI and BP is shown in Figure 1a. The 1587 subjects taking medication for hypertension were excluded from this analysis because it would have been strongly biased data towards reduced BP. Both systolic BP (sBP) and diastolic BP (dBP) were relevant to EDSI. One-way ANOVA demonstrated that these correlations were significant $(P<0.0001)$. For example, the average sBP was $122.1 \pm 17.7 \mathrm{~mm} \mathrm{Hg}$ in subjects with an EDSI of $7 \mathrm{~g}$ per day, and it was $131.5 \pm 19.0 \mathrm{~mm} \mathrm{Hg}$ in subjects with an EDSI of $12 \mathrm{~g}$ per day.

\section{Correlation between age and salt intake}

The average salt intake according to age is shown in Figure 1b. Salt intake gradually increased with age. For those subjects in their 20s, it was $6.93 \pm 2.36 \mathrm{~g}$ per day, whereas for those in their $70 \mathrm{~s}$, it was $8.03 \pm 2.00 \mathrm{~g}$ per day. One-way ANOVA showed that salt intake was significantly correlated with age $(P<0.0001)$.

\section{Association of several factors with hypertension}

We examined the associations between hypertension and several factors using multivariate logistic regression analysis (Table 2). Hypertension was defined as sBP of above $140 \mathrm{~mm} \mathrm{Hg}$, a dBP of above $90 \mathrm{~mm} \mathrm{Hg}$ or the use of medication for hypertension. Out of 10762 subjects, 3185 were classified as hypertensive. We adjusted for gender, age, body mass index, triglycerides, low-density lipoprotein/ high-density lipoprotein cholesterol, HbAlc and glomerular filtration rate as covariate factors and confirmed the absence of considerable collinearity between variables using variable-by-variable Pearson's correlation coefficient analysis. After adjusting for these covariate factors, we found that salt intake was a significant and independent factor associated with hypertension, with an hazard ratio of 1.03 (95\%
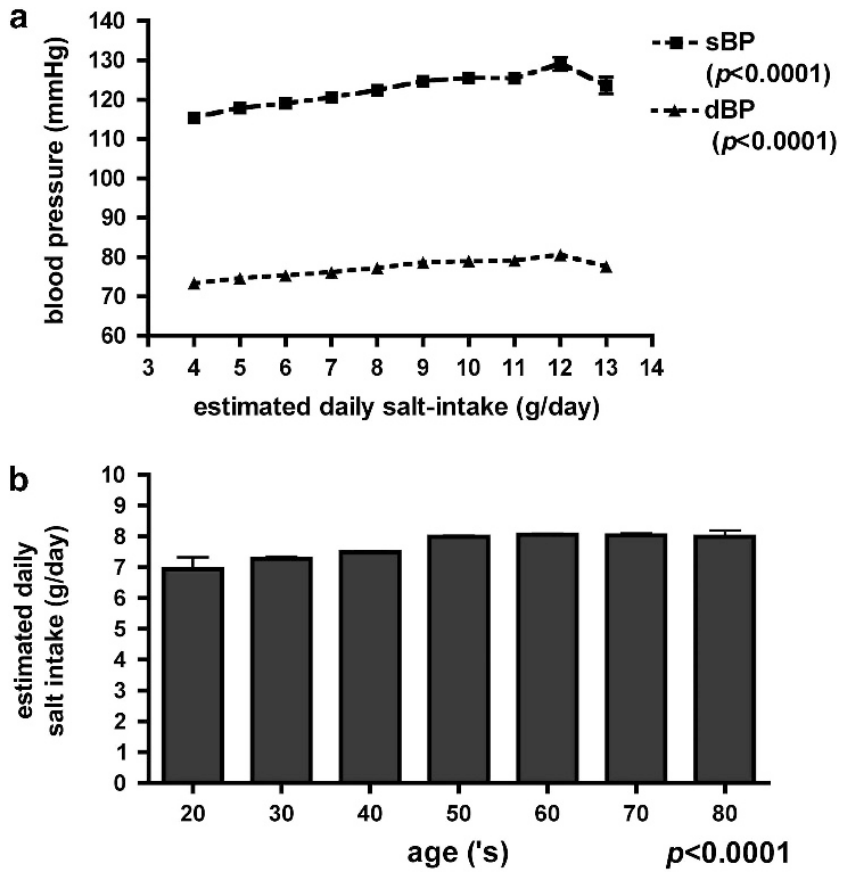

Figure 1 (a) Relation of salt intake with systolic blood pressure (sBP) and diastolic blood pressure (dBP). ANOVA showed that relevance of salt intake to $\mathrm{sBP}$ and $\mathrm{dBP}$ were significant $(P<0.0001)$. (b) Correlation between age and salt intake. One-way ANOVA showed that relevance of salt intake to age was significant $(P<0.0001)$. 
CI 1.01-1.05, $P<0.05)$. Other significant and independent risk factors associated with hypertension were gender, age, body mass index, triglycerides and low-density lipoprotein/high-density lipoprotein

Table 2 Factors associated with hypertension

\begin{tabular}{lccc}
\hline Factor & HR & P-value & $\mathrm{Cl}(95 \%)$ \\
\hline Estimated daily salt intake & 1.03 & $<0.05^{*}$ & $1.01-1.05$ \\
Gender (men) & 1.44 & $<0.001^{*}$ & $1.30-1.60$ \\
Age & 1.06 & $<0.001^{*}$ & $1.06-1.07$ \\
BMI & 1.25 & $<0.001^{*}$ & $1.23-1.27$ \\
Triglyceride & 1.00 & $<0.001^{*}$ & $1.00-1.00$ \\
LDL/HDL cholesterol & 0.80 & $<0.001^{*}$ & $0.74-0.85$ \\
HbA1c & 1.06 & 0.11 & $0.99-1.15$ \\
eGFR & 1.00 & 0.34 & $1.00-1.00$ \\
\hline Abbr
\end{tabular}

Abbreviations: BMI, body mass index; $\mathrm{Cl}$, confidence interval; eGFR, estimated glomerular filtration rate; HDL, high-density lipoprotein; HR, hazard ration; LDL, low-density. ${ }^{*} P<0.05$ was considered statistically significant. cholesterol. Salt intake remained a significant and independent risk factor after the addition of alcohol intake as a covariate (Supplementary Information).

Comparison between salt intake of hypertensive subjects and that of non-hypertensive subjects

In our comparison of subjects who took medication for hypertension ( $n=1587)$ with those who did not $(n=9175)$, we found that the subjects taking hypertension medication consumed significantly more salt (Figure 2A). Among those who did not take this type of medication, the average EDSI was $7.77 \pm 2.00 \mathrm{~g}$ per day, whereas that of the subjects taking hypertension medication was $8.18 \pm 2.24 \mathrm{~g}$ per day $(P<0.0001$, unpaired $t$-test $)$.

\section{Comparison of salt intake of subjects with and without a history of} CVD

To investigate compliance with salt restriction among patients with a history of CVD, we compared EDSIs between the subjects with and

A

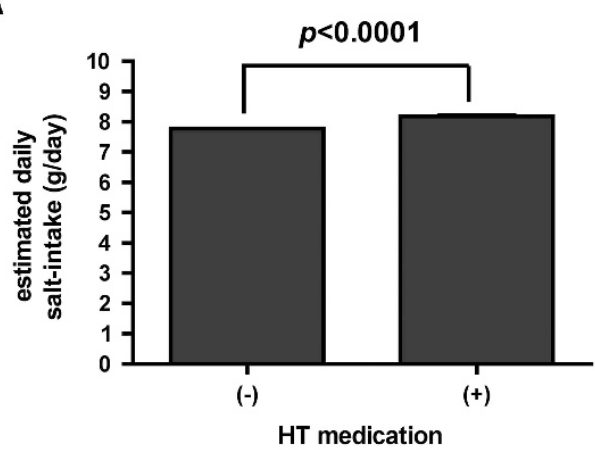

B

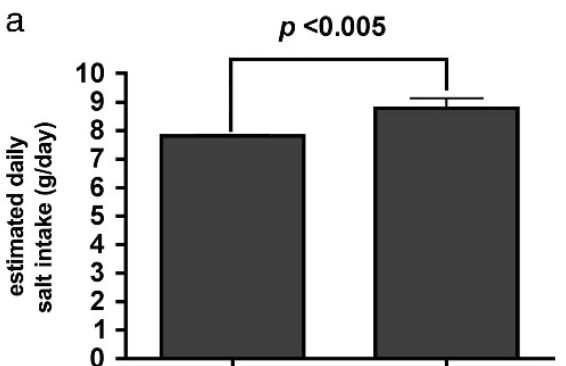

b

$(-)$

(+)

stroke

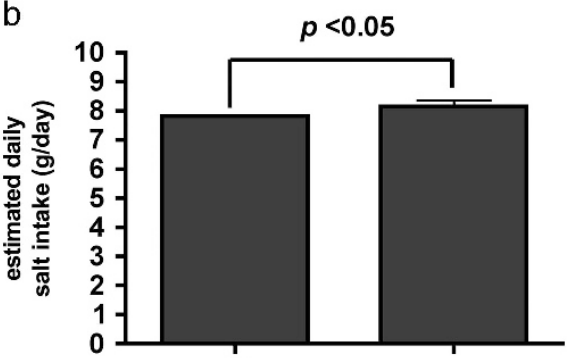

(-)

(+)

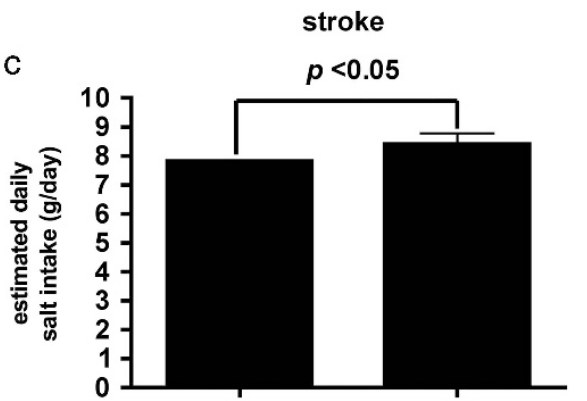

angina pectoris

(-)

$(+)$

myocardial

Figure 2 (A) Comparison between salt intake of subjects who were on medication for hypertension and subjects who weren't. Unpaired t-test analysis showed that these differences were statistically significant $(P<0.0001)$. (B) Comparison of salt intake between subjects with a history of cardiovascular diseases such as (a) stroke, (b) angina pectoris and (c) myocardial infarction, and subjects without those diseases. Unpaired $t$-test analysis showed that these differences were statistically significant (stroke: $P<0.005$, angina pectoris: $P<0.05$, myocardial infarction: $P<0.05$ ). 
without a history of diseases such as stroke, angina pectoris and myocardial infarction (Figure 2B). In all three disease groups, the subjects with a history of disease consumed significantly more salt than those with no history of disease. Unpaired $t$-test showed that these differences were statistically significant. The EDSI of 10718 subjects with no history of stroke was $7.82 \pm 2.02 \mathrm{~g}$ per day, and that of the subjects who had experienced stroke $(n=44)$ was $8.78 \pm 2.40 \mathrm{~g}$ per day $(P<0.005)$. The EDSI of 10614 subjects with no history of angina pectoris was $7.82 \pm 2.02 \mathrm{~g}$ per day, and that of the subjects who had experienced angina pectoris $(n=148)$ was $8.16 \pm 2.45 \mathrm{~g}$ per day $(P<0.05)$. The EDSI of 10708 subjects with no history of myocardial infarction was $7.82 \pm 2.02 \mathrm{~g}$ per day, and that of the subjects with a positive history $(n=54)$ was $8.41 \pm 2.78 \mathrm{~g}$ per day $(P<0.05)$.

\section{Influences of alcohol and smoking on salt intake}

We investigated whether alcohol and smoking had any effects on EDSI and found that it was positively correlated with both the quantity and the frequency of alcohol consumption (Figures $3 \mathrm{a}$ and $\mathrm{b}$ ). The EDSI of the subjects who did not drink alcohol $(n=2629)$ was $7.71 \pm 2.45 \mathrm{~g}$ per day, and that of the subjects who drank every day $(n=2395)$ was $8.06 \pm 2.11 \mathrm{~g}$ per day. The EDSI gradually increased as the quantity of alcohol consumption became greater; that of the subjects who consumed $<180 \mathrm{ml}$ per day was $7.76 \pm 1.96 \mathrm{~g}$ per day, and that of the subjects who consumed $>540 \mathrm{ml}$ per day was $8.01 \pm 2.27 \mathrm{~g}$ per day. One-way ANOVA showed that the frequency and quantity of alcohol consumption were significantly associated with EDSI (frequency of alcohol consumption: $P<0.0001$, quantity of alcohol consumption: $P<0.005)$

With regard to smoking, the EDSI of the subjects who had quit smoking was the greatest $(8.11 \pm 2.05 \mathrm{~g}$ per day) (Figure $3 \mathrm{c}$ ). The EDSIs of the subjects who smoked every day and that of the nonsmokers were $7.52 \pm 2.06$ and $7.73 \pm 1.97 \mathrm{~g}$ per day, respectively.

\section{DISCUSSION}

It is well known that increased salt intake is linked to high $\mathrm{BP}^{24}$. To prevent hypertension and reduce $\mathrm{BP}$, the reduction of salt intake is essential. Here, we examined the present state of salt intake among Japanese individuals and investigated the degree to which subjects followed their physicians' directions to restrict their intake to below $6 \mathrm{~g}$ per day. In Japan, hypertensive individuals are advised to reduce their salt intake to below this level, and it is also the recommended intake for those who have had stroke or CVD. ${ }^{17,18}$ The Dietary Reference Intake for the general population in Japan has reported that the target levels for men and women are $<9.0$ and $<7.5 \mathrm{~g}$ per day, respectively. ${ }^{18}$ The Japanese Ministry of Health, Labor and Welfare has stated that the target intake will be decreased by 2015 to $<8.0 \mathrm{~g}$ per day for men and $<7.0 \mathrm{~g}$ per day for women.

A disappointing finding of the present study was that the average salt intake of the subjects who were on hypertension medication was $8.18 \pm 2.24 \mathrm{~g}$ per day, and this value was higher than that of the subjects who were not on this type of medication $(7.77 \pm 2.00 \mathrm{~g}$ per day). Moreover, the intake of the subjects with a history of stroke, angina pectoris or myocardial infarction was also higher than that of the subjects with no history of these illnesses. These data suggest that continued efforts are needed to achieve adherence to the restriction of salt intake, especially for individuals with hypertension and for those with a history of stroke or CVD.

Nevertheless, some encouraging data were revealed by the present study. The salt intake of the younger subjects was lower than that of the elderly subjects. This may have been because the younger subjects' lifestyles, including diet, have become westernized, and Western cuisine is less salty than that of Japan. ${ }^{19}$

The moderation of alcohol consumption is recommended for the prevention of hypertension because a high level of alcohol intake is a risk factor for elevated $\mathrm{BP}{ }^{25,26} \mathrm{~A}$ meta-analysis has shown that a reduction in alcohol consumption induces significant decreases in sBP and $\mathrm{dBP}$, and a dose-response relationship was observed between the percentage of alcohol reduction and the decrease in $\mathrm{BP} .{ }^{27}$ Although there have been few studies of the relationship between alcohol intake and salt intake, our data showed that both the frequency and quantity of alcohol intake are related to salt intake. Further examinations are necessary, but one of the reasons why the reduction in alcohol intake
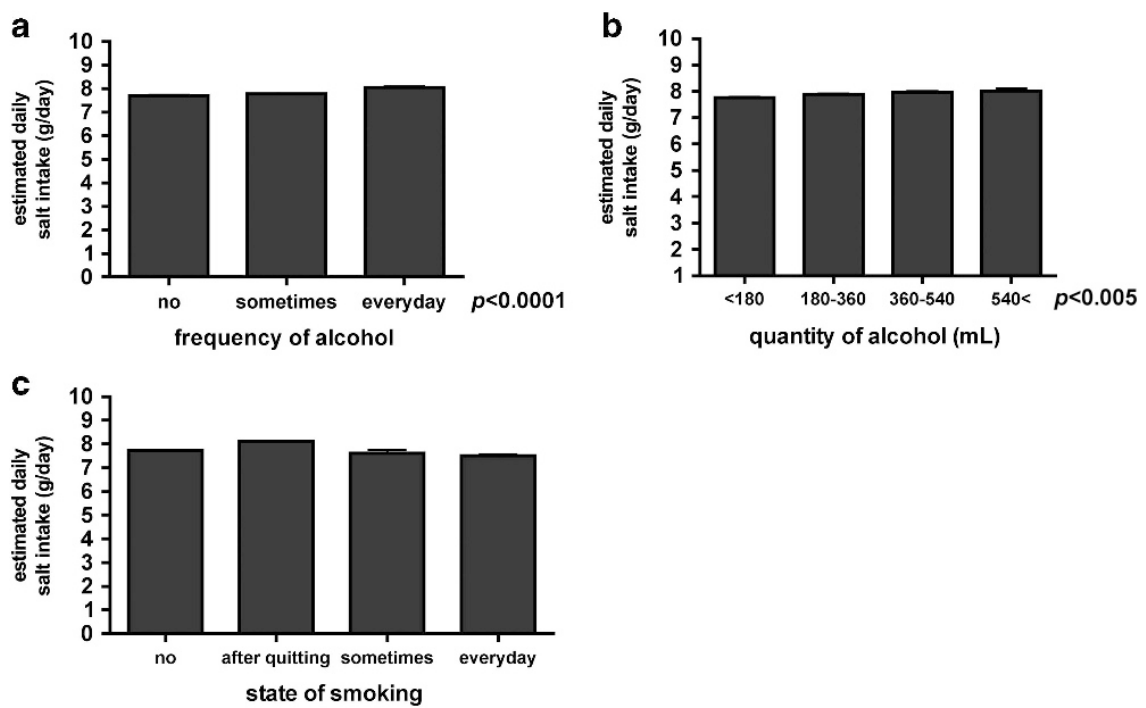

Figure 3 Correlation of salt intake with life style such as (a, b) alcohol and (c) smoking. One-way analysis of variance showed that relevance of salt intake to frequency and quantity of alcohol was significant (frequency of alcohol: $P<0.0001$, quantity of alcohol: $P<0.005$ ), and relevance of salt intake to smoking wasn't significant. 
induced a decline in BP may have been decreased salt intake because the foods that are often consumed when drinking alcohol are salty. Therefore, a reduction in alcohol consumption may be effective for preventing hypertension. It is also possible that the positive relationship between alcohol intake and EDSI was influenced by the amount of food consumed. In the present study, we found that body weight was in direct proportion to the EDSI and that the subjects who consumed higher amounts of alcohol had greater body weights (data not shown). Similarly, gender may have influenced the association between alcohol and salt intake. We found that the average EDSI of the men was higher than that of the women. This finding may have been due to a higher consumption of food by the men. Our data also showed that more males than females were heavy drinkers. On the basis of these results, we suggest that the high salt intake observed among the heavy drinkers may have been the result of the greater amount of food consumed.

BP was higher in the smokers than the nonsmokers. It has been reported that after quitting smoking, subjects' daytime BPs drop significantly, whereas nighttime BPs do not change. ${ }^{28}$ In addition, plasma concentrations of norepinephrine and epinephrine are reduced in subjects after quitting smoking. ${ }^{29}$ These data suggest that the elevation in BP induced by smoking depends on the impairment of parasympathetic nervous function rather than excess of salt intake. We did not observe a significant difference between the salt intake of the smokers compared with that of the nonsmokers. Similar to the aforementioned study, excess salt intake may not have caused the smoking-related rise in $\mathrm{BP}$.

There are several limitations of this study. The average EDSI was $7.83 \pm 2.02 \mathrm{~g}$ per day, which is lower than the value reported by the Japanese Ministry of Health, Labor and Welfare. ${ }^{18}$ This finding may have been due to several factors; first, our subjects were not representative of the general population. Individuals who undergo annual health check-ups more diligently care for their health compared with the general population. In addition, the day before an annual health check-up, people often consume smaller and healthier meals than usual. Second, we used a method based on the measurement of urinary sodium excretion, which is recommended in medical facilities. ${ }^{23}$ The data from the Japanese Ministry of Health, Labor and Welfare were obtained using a highly reliable diet-recording method. Values estimated from urine samples are typically lower than those obtained using the diet-recording method, which is partially because the entire volume of ingested salt is not excreted in urine owing to the loss of sodium in the digestive tract and through sweating. Moreover, our samples were collected in the morning. It has been reported that the estimation of salt intake using a morning urine sample is lower because less sodium is excreted in the morning. ${ }^{30}$

In conclusion, we examined the current salt intake of Japanese individuals. Our data showed that the salt intake of the individuals with hypertension and of those who had experienced stroke or CVD was high. To achieve adherence to the recommended intake, further efforts are necessary in this country.

\section{CONFLICT OF INTEREST}

The authors declare no conflict of interest.

\section{ACKNOWLEDGEMENTS}

We are grateful to all of the participants, other physicians, medical staff and other contributors to this study.
1 Intersalt: an international study of electrolyte excretion and blood pressure. Results for 24 hour urinary sodium and potassium excretion. Intersalt Cooperative Research Group. BMJ 1988; 297: 319-328.

2 du Cailar G, Ribstein J, Mimran A. Dietary sodium and target organ damage in essential hypertension. Am J Hypertens 2002; 15: 222-229.

3 Sacks FM, Svetkey LP, Vollmer WM, Appel LJ, Bray GA, Harsha D, Obarzanek E, Conlin PR, Miller ER 3rd, Simons-Morton DG, Karanja N, Lin PH. Effects on blood pressure of reduced dietary sodium and the Dietary Approaches to Stop Hypertension (DASH) diet. DASH-Sodium Collaborative Research Group. N Engl J Med 2001; 344: 3-10.

4 He FJ, MacGregor GA. Effect of modest salt reduction on blood pressure: a metaanalysis of randomized trials. Implications for public health. J Hum Hypertens 2002; 16: 761-770.

5 Kawano $\mathrm{Y}$, Ando K, Matsuura H, Tsuchihashi T, Fujita T, Ueshima H. Report of the Working Group for Dietary Salt Reduction of the Japanese Society of Hypertension: (1) Rationale for salt restriction and salt-restriction target level for the management of hypertension. Hypertens Res 2007; 30: 879-886.

6 Hirota S, Sadanaga T, Mitamura H, Fukuda K. Spot urine-guided salt reduction is effective in Japanese cardiology outpatients. Hypertens Res 2012; 35: 1069-1071.

7 Hasegawa H, Kanozawa K, Asakura J, Takayanagi K, Komuro O, Fukuda H, Tokushima H, Kogure $\mathrm{H}$, Matsuzawa M, Mitarai T. Significance of estimated salt excretion as a possible predictor of the efficacy of concomitant angiotensin receptor blocker (ARB) and low-dose thiazide in patients with ARB resistance. Hypertens Res 2013; 36: 776-782.

8 Aburto NJ, Ziolkovska A, Hooper L, Elliott P, Cappuccio FP, Meerpohl JJ. Effect of lower sodium intake on health: systematic review and meta-analyses. BMJ 2013; 346: f1326.

9 Strazzullo P, D'Elia L, Kandala NB, Cappuccio FP. Salt intake, stroke, and cardiovascular disease: meta-analysis of prospective studies. BMJ 2009; 339: b4567.

10 Teramoto T, Kawamori R, Miyazaki S, Teramukai S, Shirayama M, Hiramatsu K, Kobayashi F. Relationship between achieved blood pressure, dietary habits and cardiovascular disease in hypertensive patients treated with olmesartan: the OMEGA study. Hypertens Res 2012; 35: 1136-1144.

11 Whelton PK, Appel LJ, Sacco RL, Anderson CA, Antman EM, Campbell N, Dunbar SB, Frohlich ED, Hall JE, Jessup M, Labarthe DR, MacGregor GA, Sacks FM, Stamler J, Vafiadis DK, Van Horn LV. Sodium, blood pressure, and cardiovascular disease: further evidence supporting the American Heart Association sodium reduction recommendations. Circulation 2012; 126: 2880-2889.

12 Vennegoor MA. Salt restriction and practical aspects to improve compliance. J Ren Nutr 2009; 19: 63-68.

13 Bibbins-Domingo K, Pletcher MJ, Lin F, Vittinghoff E, Gardin JM, Arynchyn A, Lewis CE, Williams OD, Hulley SB. Racial differences in incident heart failure among young adults. N Engl J Med. 2009; 360: 1179-1190.

14 Wong MD, Shapiro MF, Boscardin WJ, Ettner SL. Contribution of major diseases to disparities in mortality. N Engl J Med 2002; 347: 1585-1592.

15 Bibbins-Domingo K, Chertow GM, Coxson PG, Moran A, Lightwood JM, Pletcher MJ, Goldman L. Projected effect of dietary salt reductions on future cardiovascular disease. N Engl J Med 2010; 362: 590-599.

16 Miyaki K, Song Y, Taneichi S, Tsutsumi A, Hashimoto H, Kawakami N, Takahashi M, Shimazu A, Inoue A, Kurioka S, Shimbo T. Socioeconomic status is significantly associated with dietary salt intakes and blood pressure in Japanese workers (JHOPE Study). Int J Environ Res Public Health 2013; 10: 980-993.

17 Ogihara T, Kikuchi K, Matsuoka H, Fujita T, Higaki J, Horiuchi M, Imai Y, Imaizumi T, Ito S, Iwao H, Kario K, Kawano Y, Kim-Mitsuyama S, Kimura G, Matsubara H, Matsuura H, Naruse M, Saito I, Shimada K, Shimamoto K, Suzuki H, Takishita S, Tanahashi N, Tsuchihashi T, Uchiyama M, Ueda S, Ueshima H, Umemura S, Ishimitsu T, Rakugi H. The Japanese Society of Hypertension Guidelines for the Management of Hypertension (JSH 2009). Hypertens Res 2009 32: 3-107.

18 Miura K, Ando K, Tsuchihashi T, Yoshita K, Watanabe Y, Kawarazaki H, Matsuura H, Kusaka M, Kai H, Kawamura M, Kawano Y. [Scientific statement] Report of the Salt Reduction Committee of the Japanese Society of Hypertension(2) Goal and strategies of dietary salt reduction in the management of hypertension. Hypertens Res 2013; 36: 1020-1025.

19 Tada N, Maruyama C, Koba S, Tanaka H, Birou S, Teramoto T, Sasaki J. Japanese dietary lifestyle and cardiovascular disease. J Atheroscler Thromb 2011; 18: 723-734.

20 Nagata C, Takatsuka N, Shimizu N, Shimizu H. Sodium intake and risk of death from stroke in Japanese men and women. Stroke 2004; 35: 1543-1547.

21 Umesawa M, Iso H, Date C, Yamamoto A, Toyoshima H, Watanabe Y, Kikuchi S, Koizumi A, Kondo T, Inaba Y, Tanabe N, Tamakoshi A. Relations between dietary sodium and potassium intakes and mortality from cardiovascular disease: the Japan Collaborative Cohort Study for Evaluation of Cancer Risks. Am J Clin Nutr 2008; 88: 195-202.

22 Matsuo S, Imai E, Horio M, Yasuda Y, Tomita K, Nitta K, Yamagata K, Tomino Y, Yokoyama H, Hishida A. Revised equations for estimated GFR from serum creatinine in Japan. Am J Kidney Dis 2009; 53: 982-992.

23 Tsuchihashi T, Kai H, Kusaka M, Kawamura M, Matsuura H, Miura K, Ando K, Maruyama S, Hayabuchi H, Takagi Y, Nakahigashi N, Sato T, Kawano Y. [Scientific statement] Report of the Salt Reduction Committee of the Japanese Society of Hypertension (3) Assessment and application of salt intake in the management of hypertension. Hypertens Res 2013; 36: 1026-1031.

24 Elliott P, Stamler J, Nichols R, Dyer AR, Stamler R, Kesteloot H, Marmot M. Intersalt revisited: further analyses of 24 hour sodium excretion and blood pressure within and across populations. Intersalt Cooperative Research Group. BMJ 1996; 312: 1249-1253. 
25 Wrobel MJ, Figge JJ, Izzo JL Jr.. Hypertension in diverse populations: a New York State Medicaid clinical guidance document. J Am Soc Hypertens 2011; 5: 208-229.

26 Marmot MG, Elliott P, Shipley MJ, Dyer AR, Ueshima H, Beevers DG, Stamler R, Kesteloot H, Rose G, Stamler J. Alcohol and blood pressure: the INTERSALT study. BMJ 1994; 308: 1263-1267.

27 Xin X, He J, Frontini MG, Ogden LG, Motsamai OI, Whelton PK. Effects of alcohol reduction on blood pressure: a meta-analysis of randomized controlled trials. Hypertension 2001; 38: 1112-1117.
28 Bolinder G, de Faire U. Ambulatory 24-h blood pressure monitoring in healthy, middle aged smokeless tobacco users, smokers, and nontobacco users. Am J Hypertens 1998; 11: 1153-1163.

29 Minami J, Ishimitsu T, Matsuoka H. Effects of smoking cessation on blood pressure and heart rate variability in habitual smokers. Hypertension 1999; 33: 586-590.

30 Kawamura M, Ohmoto A, Hashimoto T, Yagami F, Owada M, Sugawara T. Second morning urine method is superior to the casual urine method for estimating daily salt intake in patients with hypertension. Hypertens Res 2012; 35: 611-616.

Supplementary Information accompanies the paper on Hypertension Research website (http://www.nature.com/hr) 